\title{
Improving the thermal stability of one-component polyurethane adhesives by adding filler material
}

\section{Journal Article}

\section{Author(s):}

Clauß, Sebastian; Allenspach, Karin; Gabriel, Joseph; Niemz, Peter

Publication date:

2011-05

Permanent link:

https://doi.org/10.3929/ethz-b-000027873

Rights / license:

In Copyright - Non-Commercial Use Permitted

Originally published in:

Wood Science and Technology 45(2), https://doi.org/10.1007/s00226-010-0321-y 


\title{
Improving the thermal stability of one-component polyurethane adhesives by adding filler material
}

\author{
Sebastian Clau $\beta \cdot$ Karin Allenspach • \\ Joseph Gabriel • Peter Niemz
}

\begin{abstract}
The aim of the current study is to improve the thermal stability of onecomponent moisture-curing polyurethane adhesives. The approach here tends to add suitable filler materials to the adhesive and to study the resulting effects. The investigation covers mechanical tests to determine the shear strength of the glued wood joints according to EN 302-1 (2004). Furthermore, the distribution of the filler material within the adhesive is shown by means of environmental scanning electron microscopy combined with energy-dispersive X-ray spectroscopy analysis. The thermal stability of the glued wood joints could be significantly improved by adding chalk with a volume fraction of $30 \%$ to the adhesive.
\end{abstract}

\section{Introduction}

One-component polyurethane adhesives (1C PUR) are increasingly used for the bonding of wood. The properties of the reacted polymers (like elasticity, strength, temperature, and moisture resistance) are influenced by the prepolymer as well as by additives like surfactant, catalyst, and especially filler material. Filler materials are non-volatile, non-gluing matters, which are insoluble in the adhesive. Common fillers are fibres (glass fibre, mica), powders (cellulose, aluminium oxide, silica), sheet-like materials (talc), cubic materials (chalk, barytes) (Zeppenfeld and Grunwald 2005) or nowadays nano-particles (Park et al. 2009) or functionalised nanoclays (Dodiuk et al. 2006).

S. Clau $\beta(\bowtie) \cdot$ K. Allenspach · P. Niemz ETH Zurich, Institute for Building Materials, Schafmattstrasse 6, 8093 Zurich, Switzerland e-mail: sclauss@ethz.ch

J. Gabriel

Purbond, Industriestrasse 17a, 6203 Sempach Station, Switzerland 
In the past, several investigations on different types of adhesives and fillers have been carried out. The mechanical properties of polyvinyl acetate depending on morphology and chemical structure of the filler material (calcium carbonate) were investigated by Kovačević et al. (1996). The influence of the same filler on the rheological and adhesion properties of a water-based polyurethane dispersion was investigated by Muñoz Milán et al. (2005). Mansouri and Pizzi (2007) improved the performance of urea-formaldehyde and phenol-formaldehyde resin by adding micronised polyurethane powder. Sepulcre-Guilabert et al. (2001) proposed natural ultramicronised calcium carbonate and mixtures of fumed silica with natural ultramicronised calcium carbonate as filler for solvent-based PUR.

Investigations on the structure-property relationships of 1C PUR adhesives for wood, including adhesives with fibrous fillers, and their sensitivity to low wood moisture content (WMC) were carried out by Beaud et al. (2006). In contrast, Richter and Schierle (2002) and Schrödter and Niemz (2006) investigated the adhesive performance of 1C PUR under high moisture and temperature conditions. It can be concluded that the bonding strength of 1C PUR adhesives decreases with increasing WMC and temperature, respectively.

The investigations mentioned above show that the adhesion of joints produced with adhesives containing fillers was noticeably increased. The goal of this study is to investigate if comparable improvements are also achievable for the use of 1C PUR adhesives under high temperature exposure.

\section{Materials and methods}

Three laboratory adhesives were produced by Purbond (Sempach Station, Switzerland) with a varying filler material content. Thereby chalk was mixed into the adhesive using volume fractions of 15 and $30 \%$. The adhesives' parameters are listed in Table 1. All bondings were carried out with beech wood (Fagus sylvatica L.). The raw density $\rho$ at an equilibrium moisture content $\omega$ of (12 \pm 1$) \%$ amounted to $(745 \pm 34) \mathrm{kg} / \mathrm{m}^{3}$. The one-sided application of the adhesives was carried out with a spread of $150 \mathrm{~g} / \mathrm{m}^{2}$ and a pressing pressure of $0.7 \mathrm{MPa}$. To investigate the influence of the filler material content on the shear strength, 15 specimens of each group were tempered in a drying chamber for $1 \mathrm{~h}$ at 100 and $150^{\circ} \mathrm{C}$, respectively. Another group of specimens was conditioned at different relative humidities $(35,65,85,95 \% \mathrm{RH})$ at a temperature of $20^{\circ} \mathrm{C}$.

Table 1 Adhesives' structural properties

\begin{tabular}{lrrr}
\hline Adhesive & \multicolumn{1}{c}{ A } & \multicolumn{1}{c}{ B } & \multicolumn{1}{c}{ C } \\
\hline Filler content (\%) & 0 & 15 & 15 \\
Isocyanat (\%) & 15 & 15 & 60 \\
Open time (min) & 60 & 60 & 13,960 \\
Viscosity (mPas) & 6,580 & 9,340 & \\
\hline
\end{tabular}


The shear strength was determined according to EN 302-1 (2004). The specimens were tested using a displacement-controlled universal testing machine (Zwick Z100) under standard climatic conditions $\left(20^{\circ} \mathrm{C}, 65 \% \mathrm{RH}\right)$. The shear strain $\varepsilon$ was evaluated with a video-extensometer. After recording the stress-strain curve until failure, the wood failure percentage was estimated visually in steps of $10 \%$.

In addition, an environmental scanning electron microscope (ESEM) was used, and the bondline was analysed by means of energy-dispersive X-ray spectroscopy (EDX) to investigate the penetration depth and distribution of the adhesives within the wood. The EDX analysis allows for chemical characterisation of the specimens and thereby to distinguish between adhesive, wood and filler material, which contains a high amount of calcium.

\section{Results and discussion}

The shear strength of the glued wood joints increased significantly with a higher content of filler material. The graphs in Fig. 1 indicate an increase of strength at standard climatic conditions, but also after temperature exposure. The maximum increase amounted to $52 \%$ at $100^{\circ} \mathrm{C}$ using $30 \%$ filler. The wood failure percentage was also increased compared to adhesives without filler (Table 2) as a consequence

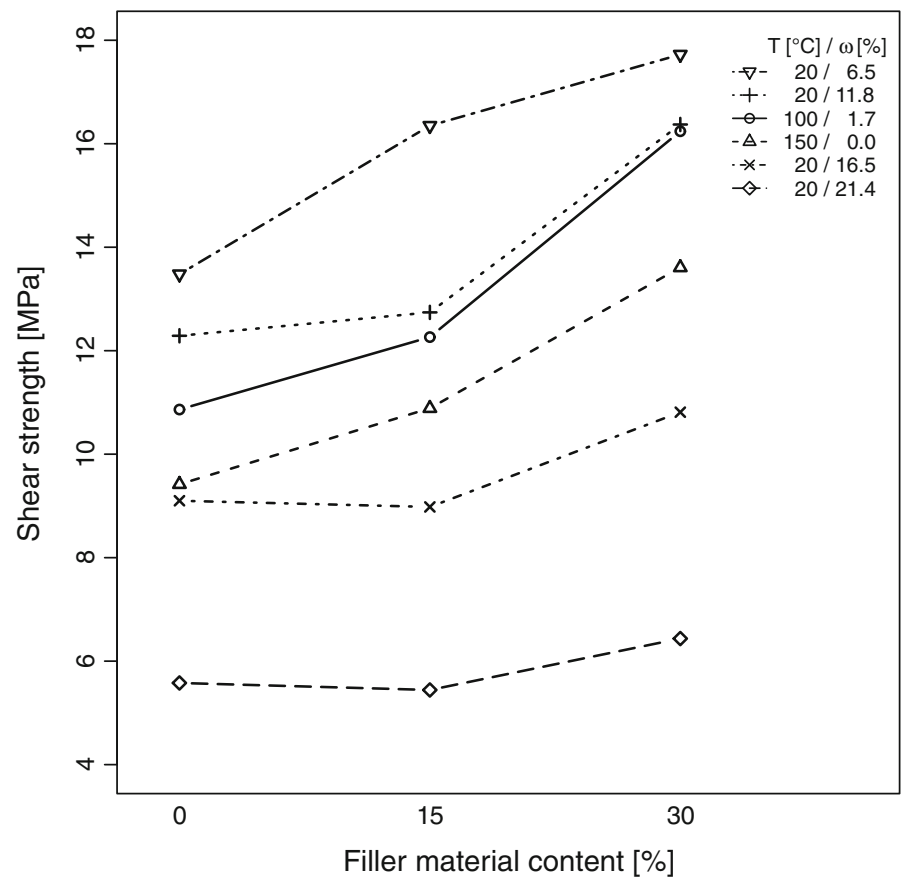

Fig. 1 Shear strength of 1C PUR adhesives depending on filler content and climatic conditions 
Table 2 Mean shear strength and median wood failure percentage of adhesive joints at varying climatic conditions

\begin{tabular}{|c|c|c|c|c|c|c|c|c|}
\hline \multirow{2}{*}{\multicolumn{3}{|c|}{ Conditions }} & \multicolumn{6}{|l|}{ Adhesive } \\
\hline & & & \multicolumn{2}{|l|}{ A } & \multicolumn{2}{|l|}{ B } & \multicolumn{2}{|l|}{$\mathrm{C}$} \\
\hline$T\left({ }^{\circ} \mathrm{C}\right)$ & $\mathrm{RH}(\%)$ & $\omega(\%)$ & $\tau(\mathrm{MPa})$ & WF (\%) & $\tau(\mathrm{MPa})$ & WF $(\%)$ & $\tau(\mathrm{MPa})$ & $\mathrm{WF}(\%)$ \\
\hline 150 & - & 0.0 & $9.42(1.30)$ & 0 & $10.89(3.28)$ & 50 & $13.61(2.28)$ & 70 \\
\hline 100 & - & 1.7 & $10.86(2.18)$ & 0 & $12.26(2.41)$ & 70 & $16.24(2.43)$ & 70 \\
\hline 20 & 35 & 6.5 & $13.48(1.85)$ & 100 & $16.35(1.47)$ & 100 & $17.72(1.90)$ & 90 \\
\hline 20 & 65 & 11.8 & $12.29(1.85)$ & 50 & $12.74(2.38)$ & 20 & $16.37(1.54)$ & 30 \\
\hline 20 & 85 & 16.5 & $9.10(2.02)$ & 20 & $8.98(2.49)$ & 0 & $10.81(1.43)$ & 0 \\
\hline 20 & 95 & 21.4 & $5.58(2.70)$ & 0 & $5.44(1.87)$ & 0 & $6.44(2.54)$ & 0 \\
\hline
\end{tabular}

$\tau$ mean tensile shear strength, standard derivation in brackets, $W F$ median wood failure percentage, $T$ temperature, $R H$ relative humidity, $\omega$ mean wood moisture content

of the better adhesion between wood and adhesive, which subsequently exceeded the wood strength.

The effect of the filler material decreased with increasing WMC. At $6.5 \%$ wood moisture, the maximum overall increase of shear strength amounted to $31 \%$ at $30 \%$ filler material. Schrödter and Niemz (2006) determined maximum compression shear strength at about $12 \%$ WMC within a similar investigation on commercially available 1C PUR adhesives. From this, it follows that after the drying process, internal compression stresses arise within the bondline, which have a positive effect in the case of tensile load.

In contrast to the specimens exposed to high temperatures, the average increase in shear strength at $21.4 \%$ WMC was relatively low (15\%); however, there was no significance at the 5\% level (Fig. 2). This means that the filler material had no substantial effect on the shear strength at high WMC. The limiting factor for the adhesive bond is the moisture resistance of the adhesive itself, independent of its filler material content. Hydrolytic effects are a possible explanation for the lower shear strength.

The main reason for the increased shear strength is the reduced penetration into the cell lumina, which is clearly shown by the combined ESEM/EDX micrograph (Fig. 3). On the left side (30\% filler), a completely filled bondline and empty pores document a good bond. The adhesive without filler (right side) on the other hand, shows a poorly bonded adherend. The adhesive filled out pores even $500 \mu \mathrm{m}$ away from the bondline; however, the joint starved instead. Already Suchsland (1958) advised that there is no relationship between the penetration depth and the bonding quality as long as the adhesive fills out the topmost surface forming cell layer.

Because calcium carbonate was used as filler material, the element calcium can be easily used for detecting the substance with EDX. It turned out that the filler material was homogeneously dispersed within the adhesive matrix (Fig. 3, picture detail) and no separations could be detected. 


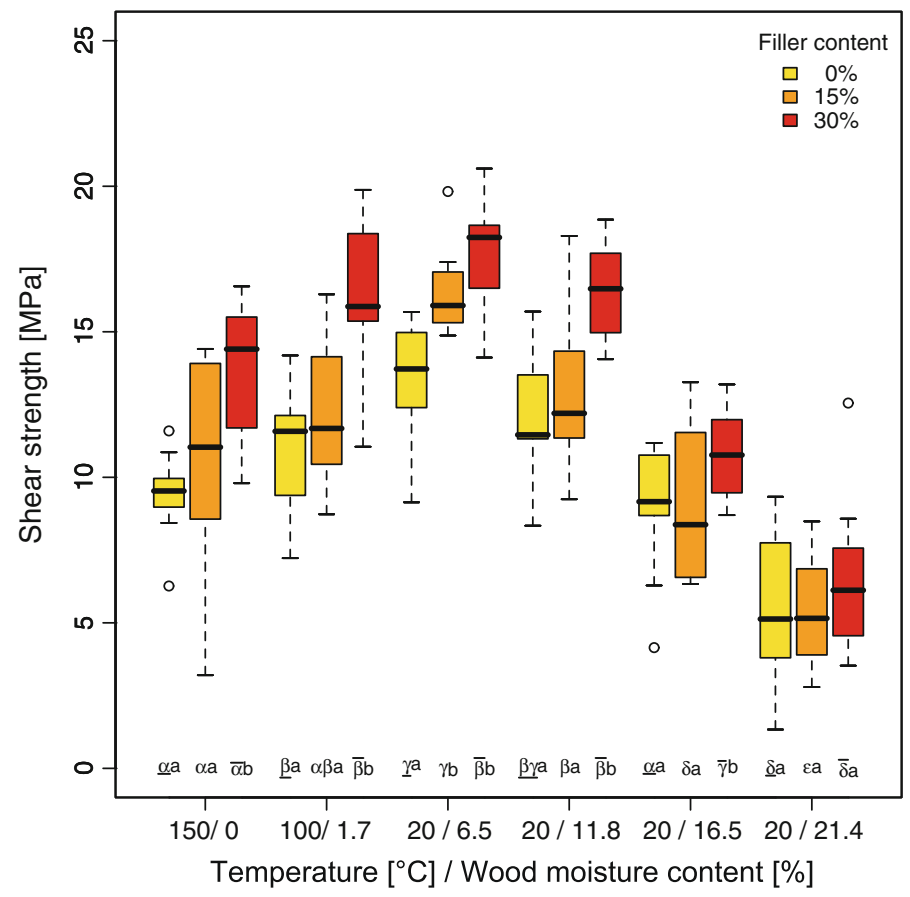

Fig. 2 Mean shear strength of 1C PUR adhesives, ANOVA indicates significantly different values $(p=0.05)$ for the factor filler content (Latin letters) and the factor temperature/WMC (Greek letters)

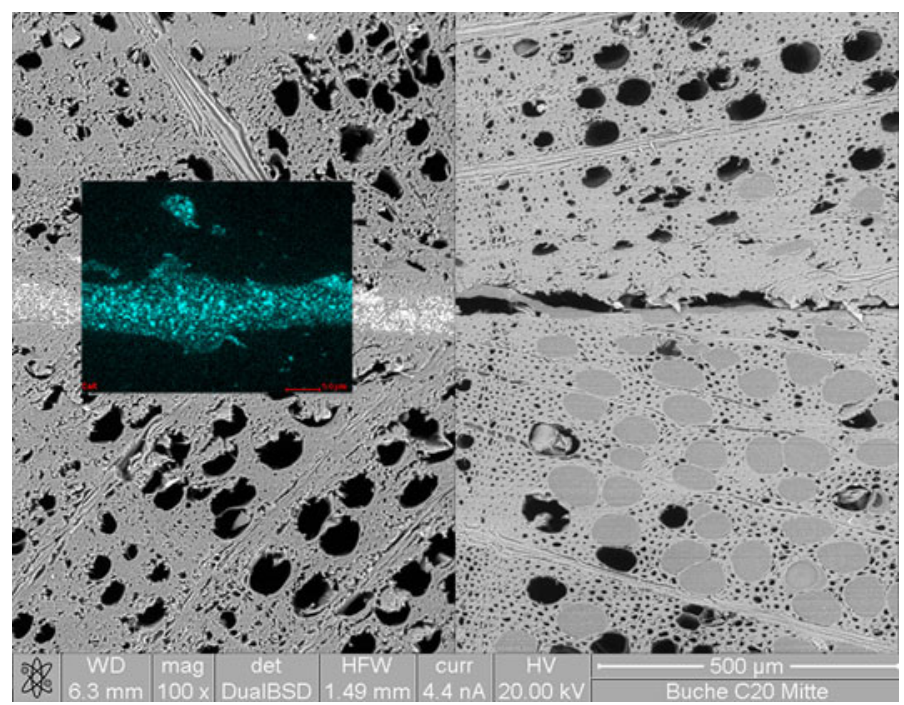

Fig. 3 ESEM micrograph of 1C PUR adhesive with $30 \%$ filler (left), without filler (right) and EDX mapping of calcium (picture detail) 


\section{Conclusion}

Chalk turned out to be a suitable filler material, which is easily addable to the adhesive, well miscible and cost efficient and it significantly improves the thermal stability of glued wood joints in the aimed temperature range. For future studies, it would be of particular interest to find suitable alternative filler materials and to determine the optimal filler material content regarding costs and bonding properties.

Acknowledgments The authors would like to thank Gabriele Peschke from the Fracture Mechanics of Concrete Group at the Institute for Building Materials (ETH Zurich) for her support at the ESEM.

\section{References}

Beaud F, Niemz P, Pizzi A (2006) Structure-property relationships in one-component polyurethane adhesives for wood: sensitivity to low moisture content. J Appl Polym Sci 101(6):4181-4192

Dodiuk H, Belinski I, Dotan A, Kenig S (2006) Polyurethane adhesives containing functionalized nanoclays. J Adhes Sci Technol 20(12):1345-1355

EN 302-1 (2004) Adhesives for load-bearing timber structures-test methods-Part 1: determination of bond strength in longitudinal tensile shear strength

Kovačević V, Lučić S, Hace D, Cerovečki Ž (1996) Tensile properties of calcium carbonate reinforced poly(vinyl acetate). J Adhes Sci Technol 10(12):1273-1285

Mansouri HR, Pizzi A (2007) Recycled micronized polyurethane powders as active extenders of UF and PF wood panel adhesives. Holz Roh Werkst 65(4):293-299

Muñoz Milán AB, Pérez-Limiñana A, Arán-Aís F, Torró-Palau A, Orgilés-Barceló AC (2005) Effect of the amount of calcium carbonate as filler on the rheological and adhesion properties of a water-based polyurethane dispersion. Macromol Symp 221:33-41

Park SW, Kim BC, Lee DG (2009) Tensile strength of joints bonded with a nano-particle-reinforced adhesive. J Adhes Sci Technol 23(19):95-113

Richter K, Schierle M (2002) Behaviour of 1 K PUR adhesives under increased moisture and temperature conditions. Lignovisionen 4:149-154

Schrödter A, Niemz P (2006) Investigations on the failure behaviour of glue joints at high temperatures and relative humidity. Holztechnologie 47(1):24-32

Sepulcre-Guilabert J, Ferrándiz-Gómez TP, Martín-Martínez JM (2001) Properties of polyurethane adhesives containing natural calcium carbonate plus fumed silica mixtures. J Adhes Sci Technol 15(2):187-203

Suchsland O (1958) On the penetration of glue in wood gluing and the significance of the penetration depth for the strength of glue joints. Holz Roh Werkst 16(3):101-108

Zeppenfeld G, Grunwald D (2005) Klebstoffe in der Holz- und Möbelindustrie. DRW-Verlag, Leinfelden-Echterdingen 